\section{Commentary: The road map for collaterals-A scenic route from the Abbey Road to the operating theater?}

\author{
Phillip S. Naimo, MD, ${ }^{\mathrm{a}, \mathrm{b}, \mathrm{c}}$ and \\ Igor E. Konstantinov, MD, PhD, FRACS ${ }^{\mathrm{a}, \mathrm{b}, \mathrm{c}, \mathrm{d}}$
}

In the early 1960s, the Beatles had their first recording session with Electric and Musical Industries (EMI) at the Abbey Road Studios (formerly EMI Recording Studios). Their momentous rise in popularity changed the face of modern music at the time. It has since been surmisedalbeit unverified - that this led to one of the biggest radiologic advanced in modern medicine. In the late 1960s, Godfrey Hounsfield, an electrical and computer engineer with no formal qualifications working for a scientific arm of the profitable EMI, began experimenting on whether images could be produced with differential $\mathrm{x}$-ray attenuation values, leading ultimately to the first computed tomography (CT, initially known as computer axial tomography, or CAT) scan. ${ }^{1,2}$ It was in 1967 that the first experimental CT scan (of a mouse) was done, which took 9 days to complete. ${ }^{3}$ Unbeknownst to Hounsfield, Allan Cormack, a particle physicist, had also shown that multiple measures of $\mathrm{x}$-ray attenuation around a target enable one to compute an image of that target. Both Cormack and Hounsfield received the Nobel Prize in Physics and Medicine in 1979.

Since its humble beginnings of 4 minutes per slice and 7 minutes per reconstruction, ${ }^{3} \mathrm{CT}$ scanning has evolved to a rapid diagnostic and investigative tool for physicians

From the a Department of Cardiac Surgery, Royal Children's Hospital, Melbourne, Victoria, Australia; ' Department of Paediatrics, University of Melbourne, Melbourne, Victoria, Australia; ${ }^{\mathrm{c} H e a r t ~ R e s e a r c h ~ G r o u p, ~ M u r d o c h ~ C h i l d r e n ' s ~ R e s e a r c h ~}$ Institute, Melbourne, Victoria, Australia; and ${ }^{\mathrm{d}}$ Melbourne Children's Centre for Cardiovascular Genomics and Regenerative Medicine, Melbourne, Victoria, Australia.

Disclosures: Authors have nothing to disclose with regard to commercial support.

Received for publication Dec 10, 2019; revisions received Dec 10, 2019; accepted for publication Dec 12, 2019; available ahead of print Feb 4, 2020.

Address for reprints: Igor E. Konstantinov, MD, PhD, Royal Children's Hospital, Flemington Rd, Parkville, VIC 3052, Australia (E-mail: igor.konstantinov@rch.org. $\mathrm{au})$.

JTCVS Techniques 2020;1:86-7

2666-2507

Crown Copyright (C) 2020 Published by Elsevier Inc. on behalf of The American Association for Thoracic Surgery. This is an open access article under the CC BY-NCND license (http://creativecommons.org/licenses/by-nc-nd/4.0/).

https://doi.org/10.1016/j.xjtc.2019.12.007

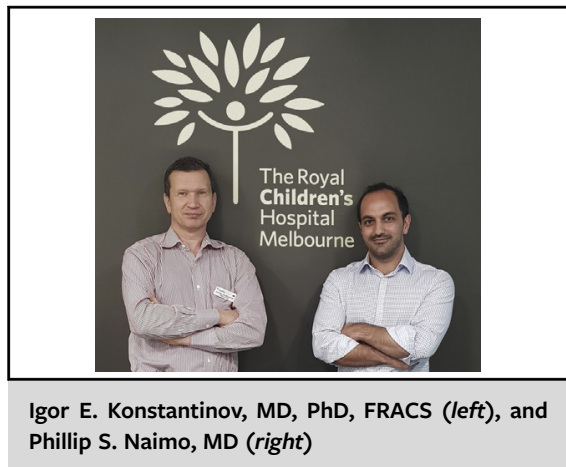

CENTRAL MESSAGE

A 3-dimensional interactive imaging reconstruction can be helpful in patients with pulmonary atresia and major aortopulmonary collateral arteries.

and surgeons alike. With such disparate uses as diagnosing an acute abdomen in the emergency department or in staging pulmonary malignancies, CT has revolutionized many areas of medicine and is continuing to do so. In the current issue of the Journal, Ghosh and colleagues ${ }^{4}$ have adopted CT angiography with digital 3dimensional reconstruction for detailed and accurate assessment of the major aortopulmonary collateral arteries (MAPCAs) in patients with tetralogy of Fallot with pulmonary atresia. MAPCAs are often tortuous and complex, which may limit such traditional imaging modalities as echocardiography and angiography. The 3-dimensional reconstruction allows an interactive and comprehensive assessment of each patient's anatomy. This would certainly benefit surgical planning. Additional 3-dimensional imaging in the interactive format could be helpful, particularly for those patients in whom the ratio of native branch pulmonary arteries to MAPCAs would sway decision making from "Let It Be" to "Come Together." 5,6

It has been a long journey from the Abbey Road to the cardiac operating theater for CT imaging. Just when it seems that CT imaging reached the limits of its usefulness, a new scenic interactive modality appears.

\section{References}

1. Sheedy P II, Stephens D, Hattery R, Muhm J, Hartman G. Computed tomography of the body: initial clinical trial with the EMI prototype. Am J Roentgen. 1976;127: 23-51. 
2. Goodman LR. The Beatles, the Nobel Prize, and CT scanning of the chest. Thorac Surg Clin. 2010;20:1-7.

3. Ambrose J. Computerized transverse axial scanning (tomography). 2. Clinical application. Br J Radiol. 1973;46:1023-47.

4. Ghosh RM, Silvestro E, O’Byrne ML, Whitehead KK. A road-map for collaterals: use of 3-dimensional techniques in tetralogy of Fallot pulmonary atresia with major aortopulmonary collateral arteries. J Thorac Cardiovasc Surg Tech. 2020;1: $82-5$.
5. d'Udekem Y, Alphonso N, Nørgaard MA, Cochrane AD, Grigg LE, Wilkinson JL, et al. Pulmonary atresia with ventricular septal defects and major aortopulmonary collateral arteries: unifocalization brings no long-term benefits. J Thorac Cardiovasc Surg. 2005; 130:1496-502.

6. Ishibashi N, Shin'oka T, Ishiyama M, Sakamoto T, Kurosawa H. Clinical results of staged repair with complete unifocalization for pulmonary atresia with ventricular septal defect and major aortopulmonary collateral arteries. Eur J Cardiothorac Surg. 2007;32:202-8. 